\title{
Sobre a Efetividade da Matemática nas Ciências Naturais: Uma abordagem Pragmática Estruturalista
}

\author{
On the Effectiveness of Mathematics in the Natural Sciences: A Pragmatic Structuralist Perspective \\ Ronaldo Pimentel $^{* 1,20}$, Frederik Moreira-dos-Santos 3,40 \\ ${ }^{1}$ Instituto Federal da Bahia, Campus de Salvador, Salvador, BA \\ ${ }^{2}$ Universidade Federal de Minas Gerais, Belo Horizonte, MG, Brasil \\ ${ }^{3}$ Universidade Federal do Recôncavo da Bahia, Cruz das Almas, BA, Brasil \\ ${ }^{4}$ Universidade Federal da Bahia, Campus Ondina, Salvador, BA, Brasil
}

\begin{abstract}
Recebido em 19 de outubro de 2019. Revisado em 31 de Dezembro de 2019. Aceito em 3 de Janeiro de 2020
Apresentamos uma concepção pragmática sobre matemática aplicada às Ciências Naturais. Se, historicamente muitas teorias matemáticas foram desenvolvidas independentemente das teorias físicas, por que muitas dessas primeiras foram tão eficazes nas teorias físicas? Defendemos a existência de um isomorfismo inicial, entre estruturas matemáticas e teoréticas, o conectamos com a busca heurística por regularidades e, em seguida, demonstramos como tal busca lança luz a nossa questão central. Porém, vale ressaltar que esse isomorfismo nem sempre é preservado quando aplicado a fins científicos. Assim, apresentamos a atitude operacional dos cientistas em usar e manipular ferramentas matemáticas para resolver problemas teóricos. A matemática pura fornece uma variedade de estruturas nas quais, quando aplicadas à física, tornam-se relações entre quantidades ou entre observáveis. Os cientistas adaptam e moldam as teorias matemáticas em diferentes níveis para torná-las ferramentas úteis para compreender as regularidades no mundo natural. Finalmente, concluímos que essa similaridade isomórfica e a plasticidade no uso operacional de ferramentas matemáticas na física nos dá a possibilidade de fazer com que a matemática (não mais tão pura) seja bem-sucedida em aplicações. Chamamos a nossa síntese de abordagens ao problema de estruturalismo pagmático. As conseqüências dessa discussão para os fundamentos da matemática também são apresentadas.
\end{abstract}

Palavras-chave: Matemática aplicada, estruturalismo pragmático, isomorfismo, Fundamentos da Física, Filosofia da Matemática.

We want to present a pragmatic conception about applied mathematics. We initiate our investigation stating such problem: If many mathematical theories were developed independently of theoretical physics, so why many of such theories have been so effective in scientific theories? We claim for an initial isomorphism between structures in mathematics and natural sciences. Then, we connect the heuristic searching for regularities and how it sheds light to our crucial question. Furthermore, it is noteworthy that this isomorphism is not always preserved when it is applied to scientific purposes. Thus, we present the operational attitude of scientists to use and manipulate mathematical tools to solve theoretical problems demanded by theoretic-empirical researches. Pure mathematics furnishes a plenty variety of structures in which, when applied to physics, they become relations between quantities or between observables. Scientists adapt and shape mathematical theories in different levels to make it useful tools to grasp regularities in natural world. Finally, we conclude that this isomorphic similarity and the plasticity of the operational use of mathematical tools in physics give us the possibility to make this hybrid language be so successful in applications. Consequences of this discussion to foundations of mathematics are presented as well. Keywords: Applications, pragmatic structuralism, isomorphism, physics, mathematics.

\section{Introdução}

O papel que a matemática exerce no mundo empírico tem sido fonte de inspiração para centenas de artigos em revistas especializadas no campo da filosofia ao redor do mundo. Muitos dos principais filósofos da ciência no séc. XX se preocuparam com o tema. A questão que iremos discutir neste artigo gravitará em torno das condições que nos permitem entender o papel bem-sucedido da matemática pura quando esta é transposta ao campo da empiria ou das ciências naturais. Esta questão será norteada, inicialmente, pelo caminho percorrido pelo físico Eugene P. Wigner em seu ensaio The Unreasonable Effectiveness of Mathematics in the Natural Sciences, de 1960 [1, p. 534-549]. Este artigo se tornou uma referência nesta temática por ter sido um dos primeiros a fomentá-lo de forma a criar uma relevante repercussão

*Endereço de correspondência: pimenronaldo@gmail.com 
acadêmica 1 , Foi escrito pouco antes de iniciar seu conturbado debate com diversos físicos proeminentes sobre o problema da medição nos Fundamentos da Mecânica Quântica e faz parte dos primeiros ensaios em torno de questões filosóficas.

Na segunda e terceira seção, mostraremos como Wigner entende o papel da matemática e da física, que estão envoltas numa "misteriosa" conexão. A matemática pode sustentar a física e vice-versa, na descoberta de explicações para os fenômenos da natureza ou impulso para uma nova teoria matemática, apesar de serem disciplinas distintas. A matemática introduz "operações hábeis" e a física é uma busca por generalidades e simetrias na natureza [1, p. 382-411]. A simetria ou invariância indica uma regularidade entre as leis da física, elevando a noção de regularidade dos fenômenos para regularidade de teorias físicas [1, p. 564-577]. Para Wigner [1, p. 283-293], [2] a invariância é tão importante que passa a ser um princípio metodológico para a elaboração de novas leis da física.

No quarto e quinto tópicos, introduziremos as discussões contemporâneas sobre o tema central deste artigo, a partir das contribuições trazidas pelos trabalhos publicados por Pincock [3], Maddy [4], Bueno \& Colyvan [5] e por Krause \& Arenhart [6]. Proporemos uma abordagem ao problema colocado por Wigner explorando mais a fundo o insight deixado por ele mesmo, na última parte de seu artigo de 1960 [1, p. 534-549] que envolve a aplicação da matemática do ponto de vista do naturalismo pragmático estrutural no nosso entender e na interpretação dos autores acima, com a variação de que a aplicação da matemática em estruturas científicas não ocorre aos moldes do isomorfismo entre estruturas matemáticas. A ciência não forma uma imagmem perfeita em estruturas matemáticas. O naturalismo pragmático que apresentamos já foi discutido em [7] e é congênere ao naturalismo na matemática de Maddy [8], ao qual denominaremos naturalismo pragmático estrutural.

No sexto tópico, relacionamos o problema da aplicação das teorias matemáticas com o importante tema do Holismo em Quine [9] e Putnam [10], em contraposição à concepção da aplicação da matemática de Maddy [8]. O holismo pressupõe a interligação entre todas as teorias científicas e a matemática, que é o contrário do naturalismo de Maddy, assim como ocorre na concepção de Wigner [1, p. 534-549] do papel da matemática nas teorias científicas.

Concluímos que a aplicação da matemática parte de estruturas abstratas que fornecem as bases para a construção de uma linguagem híbrida compartilhada pela matemática e ciências naturais, um pidgin,no sentido de Galison [11], para tatrar da aplicação do termo na fronteira de campos disciplinares. Utilizamos o termo pidgin tomado emprestado da linguística. Este termo foi criado para dar conta de certos fenômenos linguísticos comunicativos que ocorrem em fronteiras entre diferentes povos, cada um com sua própria língua. Neste contexto, os habi-

${ }^{1}$ Este artigo de Wigner está dentre os seus mais citados na área filosófica. O Google Acadêmico apontou, no dia 24 de Setembro de 2019, 2388 citações. tantes fronteiriços criam uma língua híbrida constituída por restrições e elementos estruturais de duas línguas diferentes. No nosso caso, tratamos de dois sistemas linguístico culturais distintos entre si e com estrutura comunicativa um pouco mais restrita do que aquela presente em uma língua ordinária, i.e., as linguagens $2^{2}$ matemática e científica ${ }^{3}$ Neste artigo iremos discutir como nossa síntese do debate lança luz para descrever como emerge a estrutura semântica e sintática deste pidgin específico. Isso é possível através de propriedades isomórficas entre as ciências naturais e a matemática, mas com a ajuda de uma série de adaptações da matemática para as teorias científicas, para que as teorias se tornem aplicáveis. Nesse caminho, elaboramos uma síntese dos pontos mais relevantes de diversos autores e suas contribuições para o naturalismo pragmático estrutural.

\section{A "Misteriosa" Conexão entre as Duas Disciplinas}

Wigner inicia seu ensaio defendendo uma postura cética quanto à possibilidade de uma completa compreensão das condições que explicitem como a conexão entre estes dois campos, o da Matemática e das Ciências Naturais, pode ser tão bem sucedida. Ele defende que não há nada que demonstre logicamente a legitimação desta conexão, por isso sustentá-la sem estas bases claras e bem sólidas, não passaria de um claro ato de fé na melhor das hipóteses. A matemática pertence a um campo autônomo em relação à física e seus observáveis. No entanto, isso não impede que uma disciplina possa fornecer "insights" heurísticos à outra. Wigner abre seu artigo com uma citação de C. S. Peirce: e é provável que haja algum segredo aqui em que ainda permaneça a ser descobertd 4 , p. 534 apud 14, cap. IV]. Após terminar uma primeira versão do seu ensaio e compartilhar com alguns amigos, Wigner é levado a ler o texto The Order of Nature [14], de Charles S. Pierce, através de uma sugestão de seu antigo pupilo Abner Shimony. De fato, esta sugestão cai como luva quanto a questão central tratada no ensaio de Wigner, pois tomando o fragmento de forma mais completa, Pierce diz que

devemos admitir que não parece haver qualquer coisa que dê conta em explicar a extra-

\footnotetext{
2 Explicar a distinção dos termos língua e linguagem é algo que se prologa para além dos objetivos do escopo deste artigo, nos satisfaremos, para efeito de nossa argumentação central, com a definição de que uma linguagem compreende todo conjunto de manifestações comunicativas entre os seres vivos, a língua é um destes fenômenos, portanto a linguagem abrange um escopo conceitual mais geral e, tem nas línguas naturais, exemplos de casos particulares de sua manifestação [12].

3 Neste artigo iremos aprofundar a proposta já feita por Sørensen [13, p. 73], inspirado em trabalhos publicados por Peter Galison tratando de Trading Zones entre campos disciplinares.

${ }^{4} \mathrm{O}$ fragmento mais completo do original em inglês diz o seguinte: ...it must be admitted that it does not seem sufficient to account for the extraordinary accuracy with which these conceptions apply to the phenomena of Nature, and it is probable that there is some secret here which remains to be discovered. [14, cap. IV]
} 
ordinária precisão com o qual tais conceitos [abstratos] aplicam-se aos fenômenos da Natureza. [14, p. 214 - tradução nossa; colchetes nossos]

Em seguida, seu segundo passo será responder brevemente "O que é Matemática?" e "O que é Física?". $\mathrm{Na}$ primeira resposta pode-se perceber seu forte teor pragmático ao dizer, “... Eu diria que a matemática é a ciência das operações hábeis [skillful] com conceitos e regras inventadas justamente para este propósito." [1, p. 536 - tradução nossa]. Quanto ao papel do físico ele irá dizer que "o físico está interessado em descobrir as leis da natureza inanimada" [1,537 - tradução nossa]. E então, discutirá brevemente o que entende por lei da Natureza. Segundo ele, as leis da Natureza ocupam-se em nos fornecer certas regularidades. E estas regularidades são surpreendentes por três razões:

- A primeira é a sua generalidade. Elas são válidas em qualquer ponto da Terra. Aqui ele destacará principalmente a propriedade física da invariância [1, p. 283-293].

- A segunda característica surpreendente é a possibilidade de se reduzir as variáveis que interferem no fenômeno estudado,

\section{...se duas pedras caem, simultaneamente e de uma mesma altura, de duas diferentes pessoas... [então, o princípio de invariância] ...é válido não importando se está chovendo ou não, se o experimento é armado em uma sala ou se [a pedra] será largada da Torre de Pisa, não importa se a pessoa que joga a pedra é um homem ou uma mulher. [1, p. 538 - tradução nossa; colchetes nossos]}

- E uma terceira característica que surpreende a muitos a própria existência das leis da Natureza e a possibilidade de inferi-las.

Estas declarações estão relacionadas diretamente aos princípios de invariância, tais como o princípio da conservação da energia, da carga e do momentum, porém a penúltima razão está atrelada a uma propriedade que é externa a tais princípios - apesar de esta estar relacionada diretamente às leis naturais. Refiro-me às condições iniciais que devem ser estabelecidas antes da aplicação de qualquer modelo teórico ao mundo empírico.

Quando ele se refere ao papel da Física ou da Ciência ${ }^{5}$ Wigner freqüentemente utiliza expressões tais como imagem de mundo (Weltbilt), leis naturais, regularidades, e construtos ou observáveis. Suas reflexões e leituras sobre

\footnotetext{
5 O conceito de Ciência em seus textos vai além das ciências ditas naturais e inclui também a psicologia, e a sociologia. Em nenhum momento Wigner mostrou qualquer interesse com o problema da demarcação entre as disciplinas científicas e não-científicas ou entre ciências humanas e naturais. Para não termos que dedicar uma longa seção para justificar tal posicionamento, neste artigo, optamos em tratar do domínio das ciências naturais, focando em exemplos tirados da prática investigativa na física. Porém, feitas as devidas ressalvas e aproximações, não vemos fortes razões para acreditar que nossa abordagem não poderia dar conta de justificar a efetividade da aplicação da matemática nas ciências humanas também.
}

os fundamentos da Mecânica Quântica o inspiraram a construir um quadro geral da Física composto por tais elementos. Em seu vocabulário, uma teoria do mundo natural era sinônimo de certos princípios gerais e abstratos inferidos a partir de regularidades observadas no mundo empírico [1, p. 33-47] [1, p. 261-267]

Wigner chama a nossa atenção para o fato de que as leis que conhecemos são referentes a uma parte muito pequena do mundo que conhecemos. E que os novos desenvolvimentos ocorridos na física no século XX trouxeram novas significações ao conceito de lei da Natureza e determinismo.

Ele se surpreende como os físicos utilizam os conceitos da matemática em seu campo, principalmente certos conceitos como o dos números complexos. Este fato singular é uma das razões que o leva a considerar a utilização da Matemática nas Ciências Naturais como algo na fronteira do misterioso e sem uma demonstração formal disponível. Enquanto que os conceitos da geometria elementar foram, claramente, inspirados pela relação do homem com seu espaço, ou seja, primeiramente, com a agricultura e com os primeiros modelos matemáticos que representassem a evolução espacial e temporal dos corpos celestes observáveis, o mesmo não parece ter acontecido com conceitos altamente abstratos e contemporâneos. E continua declarando como é surpreendente que a utilização de números complexos exerça um papel tão indispensável na formulação das leis da Mecânica Quântica. 7

O uso de adjetivos do tipo, "impressionante" (striking), "misterioso" (eerie), "estranho" (uncanny), "desconcertante" (baffling), "irrazoável" (unreasonable), para se referir ao sucesso da matemática aplicada a Física, nos dá uma amostra de como Wigner encarava o desafio de entender tal fato.

O físico Laszlo Tisza escreveu o seguinte comentário sobre este ensaio de Wigner:

Com sua excepcional formação básica nos dois [campos, da Física e da Matemática], Wigner tentou, mas suas conclusões são desencorajadoras. O título do seu ensaio: "A Irrazoável Eficácia da Matemática nas Ciências Naturais" se tornou uma máxima para

\footnotetext{
${ }^{6}$ Wigner, Two Kinds of Reality [1, p. 35].

${ }^{7}$ Em um dos capítulos escritos por Wigner para o livro de C. Muses e A. M. Young [1, p. 261-267] ("Consciousness and Reality", de 1972), ele desenvolve ainda mais esta questão: "...Certainly, nothing in our experience suggests the introducing of these [complex numbers] quantities...Let us forget that Hilbert space [i.e. including $\mathrm{i}=\mathrm{v}-1]$, with a Hermitian scalar product. Surely to the unpreoccupied mind, complex numbers...cannot be suggested by physical observations. Furthermore, the use of complex numbers in this case is not a calculational trick of applied mathematics, but comes close to being a necessity in the formulation of the laws of quantum mechanics. Finally, it now begins to appear that not only complex numbers but analytic functions are destined to play a decisive role in the formulation of quantum theory. I am referring to the rapidly developing theory of dispersion relations. It is difficult to avoid the impression that a miracle confronts us here [i.e. in agreement between the properties of the hypernumber $\mathrm{v}-1$ and those of the natural world]. [1, p. 266].
} 
desencorajar a busca por um "insight" mais satisfatório.

Pessoalmente, eu duvido que esta tenha sido a intenção de Wigner... [15, p. 236 - tradução nossa; colchetes nossos]

Tal não era a intenção de Wigner, que seu nível de ceticismo não foi suficientemente forte para o impedir de propor um possível direcionamento para a resolução do problema. No tópico seguinte (Is the Success of Physical Theories Truly Surprising?) Wigner arrisca uma possível resposta respaldada em três exemplos históricos, dois deles quase contemporâneos a sua época ${ }^{8}$ Destes exemplos ele conclui que a apropriação e precisão do formalismo matemático nas "leis da natureza", em termos de conceitos escolhidos para serem manipuláveis, fornecem a estas uma precisão incrível, mas estritamente limitada em seu alcance ao mundo dos fenômenos. Podemos extrair da história da Física diversos exemplos que:

\section{[...] deverão ilustrar a conveniência e precisão da formulação matemática das leis em termos de conceitos escolhidos para sua manipulação, as "leis da natureza" são de precisão quase fantástica, mas de alcance bem limitado. Par- tindo desta observação, pretendo me remeter a estes exemplos como ilustrativos de uma lei empírica da epistemologia. Junto com as leis de invariância das teorias físicas, este é um fundamento indispensável destas teorias. Sem as leis de invariância não se poderia dar fundamento de fato às teorias físicas; se a lei empírica da epistemologia não estivesse correta, nós não teríamos o encorajamento e a segurança que são emocionalmente ne- cessários, sem os quais as "leis da natureza" não poderiam ser exploradas com sucesso. [1, p.545 - tradução nossa italico nosso]}

Este termo lei empírica da epistemologia, se referindo a uma epistemologia das ciências naturais, pode soar um pouco estranho em certos círculos filosóficos, no entanto, Wigner é um empirista que acredita que mesmo os princípios mais básicos que fundamentam o nosso conhecimento partem de nossa observação e interação com o mundo. No entanto, este princípio que nos asseguraria a viável conexão entre a Matemática e a Física partiria, não de uma manipulação e recorte apenas de nossa representação do mundo natural, mas de uma manipulação em conjunto das duas disciplinas com o fim de que elas possam obter estruturas de conexão entre seus objetos com alguma analogia. O físico tomaria as regularidades

\footnotetext{
8 No primeiro exemplo ele trata da descrição precisa do movimento dos planetas e da queda dos corpos feito inicialmente por Galileu e bem formalizado por Newton; no segundo exemplo ele trata da teoria quântica elementar desenvolvida por Born, Jordan e Heisenberg; e finalmente, ele trata da eletrodinâmica quântica. Em cada exemplo ele vai apresentando o aumento do nível de precisão fornecido pelas medições, em comparação aos modelos teóricos anteriores.
}

da Natureza de um lado e manipularia as regras sintáticas da matemática do outro com o fim de que haja alguma estrutura análoga e útil para fazer previsões. Não se trata de uma confiança entre o funcionamento das regularidades como bom representante de fenômenos no mundo natural, aqui neste caso, a confiança se baseia no fato de que esta analogia entre as regularidades observadas e a sintaxe matemática funcionará com o máximo de precisão possível, ou seja, nos fornecerá leis físicas confiáveis. Ele está preocupado em explicitar os princípios que construímos a fim de possibilitar o sucesso das ciências naturais.

\section{A Simetria e as Leis Naturais}

Apresentaremos agora o princípio mais geral da ciência na visão de Wigner. Parte de sua fama na Física foi devido aos seus trabalhos que colocaram a simetria e os princípios de invariância ainda em maior evidencia. O verbete "Symmetry and Symmetry Breaking" disponível na Stanford Encyclopedia of Philosophy também reforça esta afirmação [16].

O que significam tais conceitos no vocabulário de Wigner? Ele mesmo responde:

A simetria e os princípios de invariância são regularidades, não entre eventos, mas entre as Leis da Natureza; isto, se eu conhecer alguma lei da Natureza, por exemplo, se hoje eu posso prever a futura posição da Lua a partir de duas posições recentes, então eu posso fazer inferências similares amanhã ou depois. Similarmente, as inferências quanto às posições das quedas dos corpos em um local são as mesmas referentes a outros locais. Os dois princípios invariantes em questão são aqueles referentes ao deslocamento no tempo e ao deslocamento no espaço. [1, p.383 - tradução nossa].

De modo geral quando este princípio é utilizado na Física ele é aplicado como uma estratégia metodológica com o fim de se conhecer as leis de conservação de um (ou mais) determinado observável (energia, momentum, carga, etc) em um certo conjunto de fenômenos.

Além da apropriação utilitarista e operacionalista dos conceitos da matemática nas teorias físicas, como será apresentada no tópico posterior, Wigner toma o princípio de invariância como uma linha de prumo para as leis físicas. Este princípio está no topo da hierarquização formal das teorias físicas: “...a progressão de eventos para leis naturais, e de leis naturais para simetrias ou princípios de invariância, é o que, para mim, significa a hierarquia do nosso conhecimento do mundo que nos rodeia."' 1 , pág 30 - tradução nossa] Então, ele extrai de exemplos históricos a idéia de que tal princípio foi usado tacitamente ou conscientemente como uma das formas de se testar a consistência de uma determinada lei física. Dois marcos históricos ilustrativos da Física são recorrentes em diversos textos de Wigner. São relatados momentos em que as 
investigações físicas seguiram uma abordagem inspirada num determinado princípio de invariância. Estes marcos são o surgimento da teoria cinética dos corpos de Galileu e a da Relatividade Restrita de Einstein. Porém, como bem observa Brading et al. [16], Wigner destaca que Einstein é o primeiro a ter consciência da importância do seu uso na Física teórica [2].

A importância desta abordagem frente ao controle da contingência do mundo é dada da seguinte forma: "Ser a pedra de toque para as leis da natureza é provavelmente a função mais importante dos princípios de invariância" [1, p. 330 - tradução nossa]. Em outro artigo posterior ele afirma que:

Digo mais uma vez, se alguém vier com outra lei da natureza e disser, "Sua lei natural está errada", talvez eu poderia, com maior propriedade, contradizê-lo ao lembrar-lhe, "Bem, sua lei natural não obedece um reconhecido princípio de simetria". [1, p. 384 - tradução nossa]

Quando Wigner propõe tal abordagem às leis naturais, ele não está apoiado somente em sua própria experiência que o levou a ganhar o premio Nobel de 1963, mas utiliza um caso crucial na história da ciência anterior ao seu próprio: o sucesso que Einstein teve ao criticar o modo como estavam formuladas as leis do eletromagnetismo de Maxwell, apresentando uma quebra de simetria espacial. Sua análise crítica desembocou em um dos famosos artigos de Einstein ("Sobre a Eletrodinâmica dos Corpos em Movimento") de 1905, que lança as bases da Teoria da Relatividade Restrita. Nesta citação, Wigner não somente dá o devido crédito a Einstein como também expõe sua visão empirista sobre a origem de tal abordagem:

O trabalho de Einstein estabeleceu os primeiros princípios de invariância de forma tão bem fundamentada que nós precisamos constantemente ser lembrados que eles são baseados somente na experiência. Parece-nos natural tentar derivar as leis da natureza e testar sua validade através das leis de invariância, ao invés de derivar as leis de invariância daquilo que nós acreditamos serem as leis naturais. [1, p. 285 - tradução nossa]

Wigner coloca os princípios de invariância como condições necessárias para encontrarmos novas leis naturais. Ele diz: "se as correlações entre eventos mudassem de dia em dia, e se fossem diferentes para cada ponto do espaço, então seria impossível descobri-las" [2 p. 29 - tradução nossa]. Isto ocorreria de tal maneira que esta abordagem não teria nenhuma utilidade se tivéssemos acesso direto a todas as leis da Natureza.

A citação anterior [1, p. 283-293] também nos dá uma pista para compreender melhor o que Wigner quis dizer com a sentença:

Nossa ciência é, antes de qualquer coisa, uma exploração das regularidades que se obtêm através dos fenômenos, e uma incorporação destas regularidades - as leis da natureza em princípios cada vez mais gerais (as teorias da física). [1, p. 567 - tradução nossa]

Ou seja, percebemos aqui um movimento ascendente que parte dos fenômenos aos princípios gerais da Física. Dito de outra forma, ele nos leva a crer que dentro de seu quadro geral sobre a Física (ou as ciências formais), suas teorias ou princípios gerais se resumiriam às leis de invariância (manifestas na forma de leis de conservação).

Como será discutido no decorrer deste artigo, diversos artigos explicitam esta abordagem apresentada. Esta faz parte de uma "imagem de Ciência" (weltbild), ou seja, aquilo que fornece uma estrutura unificadora ao nosso conhecimento; esta imagem é construída pela simetria dos princípios da invariância que é subjacente a todo fenômeno natural. Este é o princípio básico unificador de todas as ciências da Natureza.

Por fim, Wigner chama nossa atenção ao fato que só conseguimos trabalhar com esta abordagem sobre os fenômenos naturais porque a expansão do Universo é um processo que nos afeta muito pouco, de forma muito indireta e sutil. É isso que torna possível nossa observação através da aplicação de uma lei de simetria. Nossas observações experimentais, dos sistemas quânticos, são muito curtas comparadas com a escala temporal de evolução do Universo. Isso permite que utilizemos o princípio de invariância em relação ao observador com a precisão necessária $[1$, p. 59$]$

\section{O Isomorfismo ou Invariância Estrutural}

Devido ao alto grau de especialização das teorias matemáticas e científicas e a proliferação de vários modelos para teorias científicas do mesmo campo, tornou-se comum entre aqueles que refletem sobre a aplicação da matemática defenderem uma filosofia da matemática estruturalista. Essa concepção filosófica possibilita a existência de uma pluralidade de teorias matemáticas e compreendemos a matemática como a ciência das estruturas. Contrapondo a isso, filósofos preocupados com a matemática teórica argumentam a favor de um realismo, quando defendem um platonismo mais (ou menos) forte. O estruturalismo responde bem a esses dois casos e Maddy aceita essa interpretação como uma das faces de seu naturalismo pragmáticd 9 visto ser uma concepção bem aceita entre os cientistas.

\footnotetext{
9 Preferimos utilizar o termo naturalismo pragmático, ao invés de naturalismo metodológico, por acreditar que, apesar de não podermos fixar os objetos específicos que fazem parte do conteúdo de uma dada teoria científica ou matemática, não podemos tratar de uma teoria vazia de conteúdo. Podemos falar apenas do componente estrutural de um modelo ou estrutura matemática do ponto de vista analítico, porém não podemos confundir este recorte analítico com a possibilidade real de uma separação entre estrutura e ontologia. No mundo real, não existe linguagem sem conteúdo. A estrutura é parte sine qua non de qualquer teoria ou metateoria, porém nunca será o componente suficiente para falar sobre ela. Não defenderemos aqui que uma teoria ou linguagem não necessite de objetos para existir,
} 
Para o entendimento do porquê de considerarmos o naturalismo de Maddy como um naturalismo pragmático, convém tratarmos deste naturalismo pragmático conforme Moreira-dos-Santos \& El-Hani [7] do ponto de vista ontológico e de como ele é congênere à aplicação da matemática por meio de estruturas. $\mathrm{O}$ naturalismo pragmático emerge da prática científica e não se preocupa diretamente com a existência ou não de objetos abstratos, a não ser que esses objetos sejam inerentes às teorias científicas e sejam indispensáveis do ponto de vista da sua prática 10

Conforme vimos, Wigner afirma que a matemática é um conjunto de raciocínios operacionais [1, p. 536]. Ou ainda afirma que a matemática aplicada "(...) está meramente servindo como uma ferramenta." [1, p. 540 tradução nossa]. Essas afirmações corroboram a deflação ontológica do naturalismo pragmático. Um questionamento interessante a essa posição é se um matemático teórico pode defender a existência de objetos matemáticos absbtratos mesmo que um físico como Wigner veja a matemática como uma ferramenta, um conjunto de operações e não de teorias sobre objetos matemáticos. Como o naturalismo pragmático não se compromete, mas não impede que exista tais objetos, as crenças ontológicas distintas podem caminhar em paralelo desde que sejam justificadas pela prática científica: um matemático teórico pode precisar de objetos matemáticos abstratos se ele assume uma posição realista e um físico que usa a matemática não necessita de tais objetos.

Para introduzirmos o componente estrutural do naturalismo pragmático, tratemos na noção de estrutura e contuaremos na próxima seção. Uma estrutura é concebida como um conjunto de objetos e as relações entre esses objetos. O estruturalismo concebe a matemática como um conjunto de estruturas ou padrões, conforme pode ser encontrado em Resnik [17, cap. 10]. A concepção estruturalista da matemática como ferramenta para um cientista como Wigner é compreensível e próxima ao estruturalismo na matemática, pois a noção metodológica de simplificação de raciocínio é feita com a ajuda das relações matemáticas, não necessariamente com os objetos matemáticos. Nessa concepção, a matemática não possui significado empírico nenhum, mas não perde a sua utilidade como uma otimizadora do raciocínio, pois o significado empírico é concedido quando as estruturas matemáticas vazias de conteúdo são preenchidas. O estruturalismo na matemática de certo modo carrega essa noção ao propor que o que se estuda nas teorias matemáticas são as relações estruturais sem se importar com quais objetos (ou classes) específicos que se encaixam nessas relações. Vejamos o exemplo do teorema dual de Pappus discutido em Nagel e Newman [18] onde as

defenderemos apenas que tais entidades, ao serem bem definidas, não podem ter sua posição fixa na estrutura teórica ou linguística. Elas podem ser substituídas e/ou, em alguns casos, eliminadas sem prejuízo à estrutura teórica interna. Para compreender melhor a discussão sobre o conceito de naturalismo pragmático, ver Moreirados-Santos \& El-Hani, [7].

10 Veremos abaixo que Maddy defende o arrealismo, que é a mesma posição.

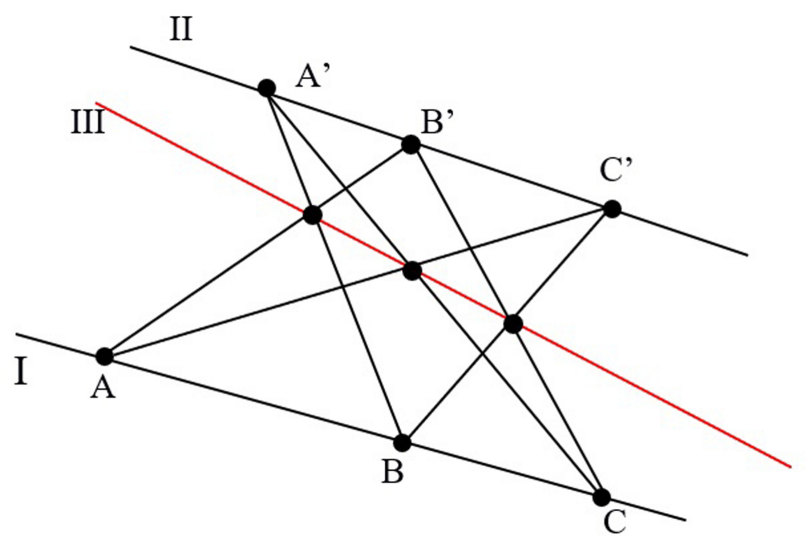

Figura 1: Adaptado de [18, p. 65]

reações estruturais são mais importantes que o próprio objeto dentro das estruturas:

A Figura 1 acima mostra três pontos distintos na linha I, A, B, C. E outros três pontos distintos na linha II, A', B', C'. Ao traçar uma reta ligando todos os pontos de ambas as retas sem que haja uma ligação entre os pontos que possuem a mesma letra conforme a sua posição, teremos a figura acima. Observa-se que os pontos dos cruzamentos das semirretas de ligação são colineares, ou seja, é possível traçar uma reta entre esses pontos. Aqui temos uma estrutura que trata dois objetos matemáticos: "reta"e "ponto" que estão numa determinada relação. Agora, ao trocar de posição na estrutura os objetos para "ponto"e "reta", mas conservando as mesmas relações, teremos o teorema dual da seguinte forma: A figura abaixo mostra três retas distintas a partir do ponto I, A, B, C. E outras três retas distintas a partir do ponto II, A', B', C'. Ao marcar um ponto ligando todas as retas de ambos os pontos sem que haja uma ligação entre as retas que possuem a mesma letra conforme a sua posição, teremos a Figura 2 abaixo. Observa-se que a reta de cruzamento das retas de ligação são copontuais, ou seja, é possível traçar um ponto de cruzamento entre essas retas:

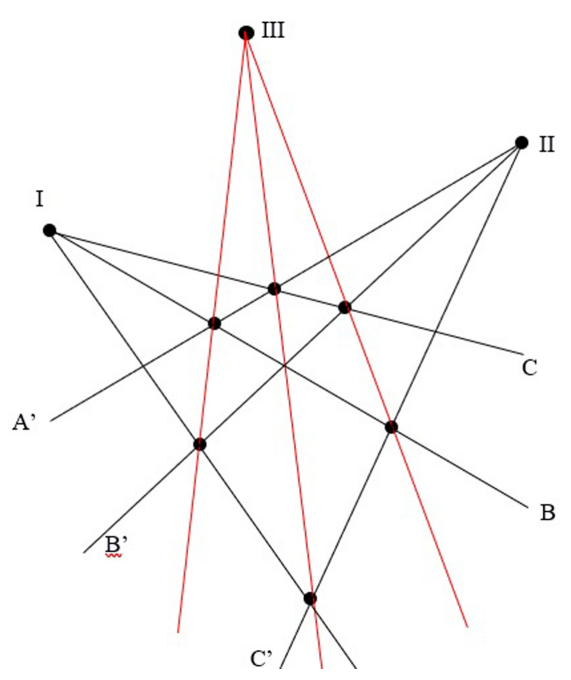

Figura 2: Adaptado de [18, p. 65] 
[18] mostra que há uma repetição de padrão no mesmo campo por conservar as mesmas estruturas, elas são invariantes ou isomórficas, ou seja, conservam o mesmo tipo isomórficd ${ }^{11}$. O isomorfismo ocorre quando há uma equivalência biunívoca entre os objetos e as relações de uma estrutura, como o conceito de ser colinear ou copontual para linhas e pontos das figuras 1 e 2 . Note que essa prática de estabelecimento de tipos isomórficos é algo comum e corriqueiro na prática matemática e faz com que alguns resultados possam ser conseguidos interpretando a estrutura com um domínio de objetos distinto em outra estrutura.

Pincock [3] utiliza o conceito de isomorfismo entre estruturas das teorias científicas e as estruturas matemáticas. Uma das estruturas que é mapeada em uma estrutura matemática não é outra estrutura matemática. A prática de aplicação da matemática é o estabelecimento de tipos isomórficos entre estruturas do mundo e estruturas matemáticas, pois a criação de um modelo científico somente se interessa pelas relações matemáticas e não pelos objetos matemáticos. Assim, o conceito de isomorfismo é ampliado para além da prática matemática. Essa concepção da matemática é explorada também em [5] e [6]. Na concepção de aplicação estrutural de [3] e [6], o processo de criação de um modelo matemático é concebido como um mapeamento das estruturas físicas em estruturas matemáticas com a criação de um isomorfismo entre estruturas. Um modelo científico é uma estrutura. Um modelo matemático é outra estrutura e, quando ambas são equivalentes, ocorre o isomorfismo entre as estruturas:

Essa estrutura então pode ser imersa em estruturas ainda maiores antes de ser imersa num modelo da teoria. Modelos da teoria em geral usam conceitos matemáticos que não têm análogos na experiência, e não podem ser diretamente aplicados na natureza. Então, embora isso seja uma descrição bem rude da relação entre teorias e dados, isomorfismos são envolvidos em todo o processo. [6, Locais Kindle 591-594, tradução nossa]

O teorema de Noether definiu como se dá este isomorfismo entre certas estruturas matemáticas e certas estruturas explicativas na física teórica. Ela demonstrou que para toda família de simetrias na estrutura físicomatemática, existe uma lei de conservação correspondente. Este isomorfismo fornece uma base significativa comum para a construção de uma linguagem híbrida entre os campos disciplinares, constitui a semântica pragmática do pidgin matemático-científico. Porém, tal característica isomórfica seria condição suficiente para o sucesso da matemática nas ciências naturais? Acreditamos que não, devido aos processos de bricolagem e a plasticidade das ferramentas matemáticas quando utilizadas para os fins investigativos da física. Buscaremos dar conta destas

\footnotetext{
11 Neste artigo iremos tratar o significado matemático de isomorfismo como sinônimo do seu termo equivalente utilizado na física, a invariância.
}

questões a partir de duas vias principais. Entretanto, neste artigo, iremos desenvolver a segunda (b), deixando a primeira (a) para uma publicação posterior:

1. Boa parte da estrutura matemática é composta por formas de invariâncias. Dadas por equivalências e proporções representadas na forma de equações e teoremas. Na física, tal invariâncias se apresenta na forma de regularidades, simetrias e leis de conservação. De forma geral, a matemática aplicada é o encontro destas duas estruturas. Historicamente, tanto a física quanto a matemática, por influência platônica e pitagórica, sempre tiveram uma busca em comum, i.e., estados, processos e/ou princípios que permanecem a despeito da contingência histórica da Natureza ou de seu devir. O lugar deste papel de permanência pode ter mudado de lugar em cada pensador da antiguidade, porém com o surgimento do tipo de naturalismo que foi estabelecido com o surgimento das ciências modernas, tal constância e permanência foi buscada nas propriedades universais intrínsecas da matéria (tese monista). Com o advento do mecanicismo cartesiano, de um lado, e dos modelos atomistas, de outro, esta passa a ter estrutura. Constrói-se, então, uma linguagem formal que nos permite a observar e falar sobre a existência de simetrias na Natureza e leis de conservação. Enquanto, na matemática, esta busca pela permanecia e imutabilidade (que apareceu fortemente em Pitágoras e Platão) foi fixada, inicialmente, em seus entes ou substâncias com seus lugares naturais, ao passar dos séculos, esta passou a ser buscada, também, em suas estruturas. Portanto, não nos surpreende que determinadas conservações e invariâncias estruturais e funcionais, na linguagem formal da física e da matemática, tenham historicamente impulsionado uma a outra mutuamente em alguns casos.

2. Deve-se ressaltar que este isomorfismo está a serviço de uma certa operacionalidade quantitativa e empírica quando é transposta para a Física. Os físicos veem a matemática, quando não criam sua própria estrutura sintática, como "depósito" mnemôniç ${ }^{12}$ [4], [8] de estruturas formais que podem servir como ferramenta para a construção de um modelo sintático e heurístico para a investigação no campo da física. Tais investigadores irão remodelar a estrutura dos teoremas e das equações sempre que necessário, de forma ad hoc, retirando ou recolocando certas propriedades que não derivam da estrutura matemática original. Por isso, não se deve tomar os isomorfismos dos dois domínios como a aplicação de iguais iterações paralelamente. É uma apropriação livre de uma estrutura que mostra uma equivalência entre grandezas ou simetrias que se apresentam a despeito de certa(s) variante(s) numa equação ou função. Tendo em vista que nem todas

\footnotetext{
12 Este conceito de "depósito" (warehouse) utilizado nos termos de Penelope Maddy nos faz recordar daquele utilizado por Ferdinand Saussure: "depósito mnemônico" de signos linguísticos [19, p. 22].
} 
as consequências formais derivadas do modelo matemático são, necessariamente, assimiladas pelos físicos. O resultado do modelo formal-representacional é um híbrido de desdobramentos provenientes da própria sintaxe do modelo matemático, com cortes, transliterações e bricolagens ou enxertos de proposições ligadas a representações provenientes de resultados empíricos.

Essa concepção estrutural mantém uma suspensão do juízo sobre o realismo na matemática e por isso aceita a crença comum entre os cientistas de que a matemática pode ser transposta tomando apenas a sua parte estrutural, assim, esta estaria pronta para receber o conteúdo dos objetos tratados pela ciência. Aqui, o interesse da matemática, seus objetos e métodos, continuam distintos do restante das demais ciências. A matemática aplicada às ciências naturais é mesmo uma linguagem mutilada e híbrida (pidgin), onde extrai apenas a estrutura de certos modelos ou teorias que interessam aos cientistas e que serão preenchidos com informações empíricas. Quando aplicada às demais ciências, a matemática pode ser vista como uma ferramenta de representação da física ao passo que o matemático pode manter uma posição realista na matemática independente do que pensa o físico ou qualquer outro cientista sobre a sua aplicação. Essa concepção realista sobre a matemática não influencia na concepção estruturalista de aplicação da mesma, nem na concepção estruturalista em geral, pois o que muda são os objetos tratados em cada situação. Nas ciências, um tipo de objeto, na matemática teórica, outro tipo de objeto, mas permanecendo a estrutura da teoria matemática.

\section{Isomorfismos e a Aplicação da Matemática}

$\mathrm{O}$ argumento de indispensabilidade da matemática nos diz que devemos aceitar a existência de objetos matemáticos, impondo um tipo de platonismo sobre nós a partir da ciência aplicada. Para dizermos de outra maneira, se as melhores teorias científicas contêm referências a objetos matemáticos abstratos, a crença na existência desses objetos é inevitável. Muitos filósofos, em sua maior parte naturalistas, defendem essa concepçã ${ }^{13}$ no entanto, na aplicação estrutural isso não acontece necessariamente, pois o foco dessa concepção é que objetos matemáticos são posições em padrões, como é o caso do estruturalismo de Resnik:

A matemática da teoria de conjuntos se aplica a qualquer hierarquia iterativa se essa é gerada por uma relação composicional ou não. Isto é porque, do ponto de vista da teoria de conjuntos, conjuntos são simplesmente posições nas hierarquias iterativas. Eles aparecem para nós tendo uma estrutura interna

\footnotetext{
13 Para um entendimento mais completo dos argumentos de indispensabilidade, consultar o livro de Mark Colyvan, The Indispensability of Mathematics, [20].
}

somente porque usamos linguagem composicional e analogias ao elucidar suas relações. Mas enquanto esse modo heurístico por essencial para nosso pensamento sobre a hierarquia, e até na compreensão de axiomas e provas, não é refletido no conteúdo da teoria de conjuntos em si. Pois, de outra forma, poderia distinguir as hierarquias iterativas composicionais - aquelas com uma relação 'real' de pertença - daquelas que não têm uma relação de pertença "real". [17, p. 213 tradução nossa].

No estruturalismo, a concepção ontológica da matemática é diferente, pois há um lugar de um possível objeto que pode ser substituído por qualquer objeto que se encaixe nos padrões ou relações entre os objetos. A matemática é a ciência dos padrões das relações entre os objetos ou também a ciência das estruturas. Por exemplo, a teoria de conjuntos possui um objeto específico que são os conjuntos que estão numa hierarquia de relação de pertença, enquanto visto sob o ângulo da axiomática concreta, na diferenciação entre axiomáticas ${ }^{14}$ Do ponto de vista da axiomática abstrata, qualquer objeto que se comporte como um conjunto e obedeça aos padrões da hierarquia que pertença pode ser substituído no lugar de um conjunto, preservando as relações entre os objetos [6], ou seja, quando certos objetos substituem outros, temos a manutenção de um isomorfismo entre as teorias.

Na concepção estruturalista de aplicação da matemática, o isomorfismo entre estruturas passa a ser mais evidente, mas o problema ontológico do realismo não desaparece. O realismo se torna periférico em relação à discussão da aplicação de uma estrutura, que é a repetição de um padrão matemático num modelo científico. Pouco importa qual objeto realmente se encaixa numa posição de objeto, mas o que importa é que as relações estruturais sejam respeitadas e úteis para a ciência. Assim, o problema da existência de objetos matemáticos se situa fora do problema da aplicação da matemática. A respeito disso, diz Pincock: "Se as relações são genuinamente externas, então a conexão entre matemática e o mundo físico não afetará a necessidade da verdade matemática." [3, p.145 - tradução nossa]. Ou seja, pouco importa se as teorias matemáticas afirmam ou negam a existência de objetos matemáticos, a verdade sobre a existência desses objetos está além da prática de criação de estruturas, sendo restrita, e, portanto, sustentada num conjunto restrito de situações. O cientista pode restringir o que ele considera como objeto, valendo apenas para o caso dos objetos científicos.

O matemático pode considerar, para efeitos da prática, que números e conjuntos existem, como está descrito nos axiomas das teorias matemáticas, mas, fora da matemática, essa constatação não faz nenhum sentido, restando a estrutura como um conjunto de raciocínios pronto para

\footnotetext{
14 Axiomática concreta é uma teoria axiomática sobre um domínio de objetos bem específico. Por exemplo, a aritmética de Peano é concreta pois trata de um domínio bem específico: números naturais ou conjuntos para a teoria de conjuntos [9].
} 
ser utilizado. O que interessa são os lugares dos objetos nas estruturas, que podem ser preenchidos com objetos físicos. Objetos físicos e objetos matemáticos possuem realidades independentes entre si. O isomorfismo não estabelece nenhuma influência entre objetos físicos e objetos matemáticos e como os objetos e estruturas matemáticas possuem existências independentes disso, as relações são meramente externas às relações da matemática pura. A aplicação é possível somente porque existe um mapeamento entre as estruturas físicas e matemáticas. O mapeamento adequado a ser realizado das estruturas físicas nas estruturas matemáticas é aquele que tende a conservar as estruturas físicas de modo que a aplicação da matemática seja útil na dedução de explicações testáveis na física e não refutadas. A partir dessa perspectiva, o argumento de indispensabilidade não se sustenta pela aplicação da matemática.

Isomorfismo entre estruturas funciona bem entre teorias matemáticas. As estruturas são embebidas em estruturas com cardinalidade maior e terminam gerando uma teoria tão geral que engloba numa única estrutura uma quantidade muito grande de teorias. Já o mapeamento de estruturas científicas em uma teoria matemática não é tão perfeito. Numa teoria científica sempre há um conjunto de fórmulas que são o modelo ou axiomática concreta da teoria (axiomática concreta). Para a derivação das consequências dessa teoria, os raciocínios matemáticos são concatenados (axiomática formal e abstrata). O isomorfismo pode falhar quando se considera a axiomatização de teorias que não são matemáticas, exigindo uma série de adaptações, generalizações e bricolagens para a tradução de proposições da física numa proposição matemática.

$\mathrm{O}$ isomorfismo funciona muito bem em exemplos bem simples de aplicação: A soma das maçãs numa mesa é um deles: basta mapear a situação na aritmética que o isomorfismo do resultado é garantido. Em modelos científicos mais complexos essa situação não ocorre. Modelos matemáticos de teorias científicas são assintóticos, ou seja, não descrevem completamente uma situação empírica, sempre são a caricatura de uma situação real. Quando um problema real é modelado, informações sobre fenômenos podem ser perdidas.

$\mathrm{Na}$ maioria das vezes em que se recorre à matemática, não ocorre um isomorfismo completo preservando a cardinalidade das estruturas de ambos os lados. Isso acontece porque teorias matemáticas tendem ter uma estrutura de cardinalidade maior que as usadas dentro das teorias científicas ou porque a complexidade das situações não pode ser mapeada completamente sem que se perca a objetividade da teoria. Não é simplesmente um mapeamento de uma estrutura dentro da outra estrutura o que se faz na aplicação da matemática. Existem inúmeras maneiras de mapear uma teoria científica numa estrutura matemática [5, p. 345].

A natureza não se comporta totalmente como a matemática. Se uma teoria física é mapeada completamente dentro das estruturas matemáticas, corre-se o risco de acontecer uma extrema idealização no modelo matemático da teoria, tornando os cálculos matemáticos possíveis, mas com uma distância enorme entre o real e o calculado. Por outro lado, um modelo complexo que represente fielmente uma situação empírica torna os cálculos muito mais complexos, restringindo consideravelmente a inferência de qualquer dado empírico relevante a partir deste modelo. Um modelo científico-matemático é considerado uma caricatura que simplifica a realidade de um lado e adapta a riqueza das estruturas matemáticas do outro. Assim, temos a dimensão pragmática da semântica e sintaxe do pidgin matemático-científico.

Uma situação que ocorre é a que a física exige, frequentemente, a criação de teorias matemáticas que deem conta destas caricaturizações (fruto desta linguagem híbrida de fronteira), um novo campo de estudo para a matemática que vem de problemas da ciência. Estas teorias passam a estar dentre aquelas possíveis de serem encontradas numa vasta gama de estruturas matemáticas e então passam a ser desenvolvidas até o ponto de se tornarem teorias axiomáticas abstratas.

Outra situação é quando as teorias abstratas, quando interpretadas, levam à novas descobertas científicas. Wigner usou de uma teoria matemática ainda não aplicada em sua época para resolver problemas da teoria de grupos. Nesse caso, um problema científico é levado a se adaptar a uma teoria matemática, uma axiomática abstrata, ainda não utilizada em nenhuma teoria científica anteriormente, ou seja, os matemáticos estavam desenvolvendo a teoria fora do âmbito da aplicação. Em ambos os casos acima, a matemática é vista como um "depósito" mnemônico [4], [8] de estruturas pronto para ser usado nas aplicações das ciências empíricas que, circunstancialmente, leva ao avanço da ciência: "Acima de tudo, em muitos casos é patentemente claro que há mais estrutura ou no mundo ou na matemática." [5, p. 348 - tradução nossa].

Quando o mundo possui mais estruturas que a que está sendo usada para representar a teoria através da matemática, adaptações teóricas com o intuito de simplificar as teorias podem ser feitas ou adaptações na matemática usada podem ser feitas, como a troca para uma geometria não-euclidiana na teoria da relatividade geral.

Quando a matemática possui mais estruturas que a teoria sobre o mundo, significa que a teoria foi desenvolvida como matemática teórica antes da aplicação em alguma teoria física. A teoria fica disponível como possível estrutura a ser utilizada e é aqui que entra o papel da matemática nas descobertas da física. $\mathrm{O}$ uso de matemática teórica nunca antes usado pela ciência pode levar a algum avanço através de novas descobertas. O exemplo dessa situação é a dilatação do tempo de Lorentz, dado por Bueno e Colyvan [5], descobertas na era pré-teórica da relatividade especial. No início do século XX, a dilatação do tempo encontrada por Lorentz, era considerada, por ele mesmo, como um mero artefato matemático. Lorentz possuía algumas intuições pré-relativísticas sobre o tempo, mas nesse período não chegou a tecer considerações sobre isso. A surpresa é que a matemática aqui não era um mero facilitador de cálculos, mas as expressões passaram a ganhar sentido físico nas aplicações com a dilatação do tempo. A consideração da aplicação não 
pode ser vista como um isomorfismo estrutural completo. Há adaptações que dependem do contexto em que a matemática é aplicada. Essas adaptações é que tem a ver com as idealizações matemáticas, e as interpretações e operacionalizações da física. É nesse sentido que [5] chamam a aplicação de inferencial.

Este tipo de inferência que dá sentido ao papel heurístico exercido pelos modelos matemáticos transpostos à investigação científica. Levar a novas descobertas na ciência é um importante papel da aplicação da matemática, mas isso não indica em nenhum momento uma realidade pitagórica, em que há a necessidade de se confiar na existência de objetos matemáticos. A própria prática de aplicação da matemática envolve um processo de idealização que deve buscar um equilíbrio. A adaptação dos cálculos feita por um físico, sobre seus modelos teóricos, deve estar em equilíbrio com as idealizações matemáticas que são necessárias para a criação de um modelo matemático.

Um modelo físico-matemático ${ }^{15}$ força a simplificação da realidade, enquanto que o avanço da investigação empírica, na busca do aumento da precisão no processo de medição e do controle de uma gama cada vez maior de fenômenos, tende a introduzir elementos que aumentam a complexidade do cálculo, forçando a adaptações do resultado matemático. Um modelo físico-matemático, mesmo que seja uma idealização grotesca e caricaturada da realidade, funciona. Sempre algumas variáveis dos fenômenos são desconsideradas, números e medidas são arredondadas, generalizadas, etc.

Essas adaptações são seletivas ou muitas vezes a partir de cópias de equações matemáticas já usadas em outros campos. Equações usadas em fluxo de calor podem ser as mesmas para fluxo de fluidos ou tensão de membranas. Essa situação é muito semelhante ao nosso exemplo de geometria projetiva, pois a estrutura permanece a mesma mudando unicamente os objetos, apesar das adaptações ali feitas para satisfazerem os requisitos da estrutura do mundo [4, p. 316].

Essa característica da aplicação da matemática mostra que os cientistas promovem uma simplificação dos fenômenos e medidas e/ou uma simplificação nas teorias matemáticas que eles querem usar. Novamente, essas estruturas não englobam todas as possíveis estruturas da matemática. A realidade da matemática é muito mais rica que aquilo que é selecionado para estudos em ciência aplicada. Disso se conclui que não há qualquer implicação ontológica das teorias físicas na matemática, ou seja, “(...) nossa descrição científica do mundo físico não nos diz nada sobre a ontologia abstrata." [4, p. 317 - tradução nossa]. A aplicação da matemática não é um milagre e não há outra explicação que não seja mera coincidência de estrutura: ${ }^{16}$ e quando essa semelhança não é alcançada, o cientista manipula e adapta de acordo com a sua

\footnotetext{
15 Constituído linguisticamente por um pidgin matemático-científico específico e direcionado para representar uma classe específica de fenômenos na Natureza.

16 Não sendo uma completa coincidência devido ao compromisso que estes dois campos sempre tiveram com a busca de estruturas conservativas e invariantes.
}

necessidade. Esse aspecto é puramente circunstancial, pois cada adaptação matemática ou empírica é motivada pelas limitações presentes no contexto da aplicação e é nesse sentido que a aplicação da matemática deve ser entendida.

Lembremos então do desafio deixado por Wigner, quanto ao papel indispensável das propriedades do número imaginário na teoria quântica. O destaque que temos dado à manutenção da estrutura formal, a despeito da substituição dos objetos, se mantém válido mesmo para o caso da utilização das propriedades do número imaginário na teoria quântica. Estas se tornam desnecessárias quando representamos os estados quânticos dentro de um espaço que se encontra no domínio dos números reais, a partir da estrutura algébrica de Lie-Jordan. Tal transliteração pode ser feita mantendo-se a estrutura teórica interna, sem perda semântica significativa, quando se busca representar a evolução dos estados quânticos.

\section{Contra o Holismo de Quine/Putnam: reflexões sobre as consequências do naturalismo pragmático nos fundamentos da matemática}

Holismo é a tese de que toda a ciência está interligada formando um corpo unificado de crenças. Essas sentenças estão interligadas em relações lógicas ou matemáticas, formando um "campo de força" [21, p. 42]. A analogia do campo de força parece convir para o holismo, pois uma perturbação nas extremidades de um campo de força pode ser tão forte que atinge o centro do campo. Como as sentenças estão interligadas, todas elas são úteis para a constituição de significado dos termos utilizados e as consequências de um teste empírico reverberam em toda a ciência. No fundo, um defensor do holismo termina por defender que o significado de qualquer termo científico ou matemático possui significado empírico também. Quine diz que "Seria errado também supor que nenhuma sentença de uma teoria tem seu sentido empírico separável. $[9$, p. 71 - tradução nossa $]$ ". Enquanto Putnam diz, sustentando um holismo confirmativo, que “(...) verdades analíticas não são irrevisáveis (nenhuma verdade é)." [10, p. 97 - tradução nossa].

Perante o holismo, as teorias matemáticas e físicas são dependentes e ambas estão sendo sustentadas pelo teste empírico. Uma concepção estruturalista da matemática não possui compromisso com esse tipo de holismo, visto que ambas as disciplinas são independentes. Mesmo que a matemática seja um instrumento usado com sucesso nas teorias científicas, ela não é a linguagem do mundo e não tem condições nenhuma de responder de modo exato o que realmente existe no mundo e nem as teorias científicas podem dizer o que existe ou o que não existe dentro da matemática. Essa separação é a base do arrealismo de Maddy:

Ela não vem para suas investigações com qualquer preconceito a priori contra objetos abstratos ou com quaisquer preconceitos sobre o 
que o conhecimento deve ser como que parece descartar o conhecimento de conjuntos. Ela não argumenta que o conhecimento da teoria de conjuntos é problemático ou impossível em princípio; ela simplesmente inspeciona a evidência em suas mãos e conclui que ela não confirma a existência de conjuntos ou a verdade de nossa teoria sobre eles. [8, p. $97-98$ - tradução nossa]

Porém, essa posição não impede a defesa de um realismo vindo dos fundamentos da matemática. Realismo nos fundamentos não influencia no arrealismo na aplicação, pois a aplicação não tem condições nenhuma de responder sobre os objetos matemáticos. Dentro da filosofia da matemática, o realismo é a tese de que existem objetos matemáticos como números, conjuntos, funções, etc. Um teorema matemático ou um axioma afirma a existência de objetos matemáticos, ou seja, é algo frequente e aceito na prática matemática. Dentro dessa concepção de realismo existe a concepção do realismo fraco. O realismo fraco assume a existência de objetos desde que a teoria possua sentenças verdadeiras sobre esses objetos, ao mesmo tempo que mantém toda a lógica do terceiro excluído e não-construtivismo das teorias matemáticas. A diferença em relação a um realismo forte é que a justificativa para a existência ou não de objetos dentro de uma teoria são os argumentos da própria teoria. Nem o argumento de indispensabilidade da matemática para teorias científicas e nem a possibilidade de um platonismo na matemática forte são caminhos para esse realismo fraco. [4], [8]

A teoria de conjuntos é um dos campos onde mais ocorre defesa de um realismo. A teoria de conjuntos é autônoma, com a possibilidade de introdução de objetos matemáticos abstratos a partir da sua prática matemática e nada além da própria teoria pode afirmar a existência desses conjuntos. Se a teoria de conjuntos afirma a existência de entidades abstratas e grande parte da comunidade que desenvolve essa teoria as aceita, então esses objetos existem para aquela comunidade. "(...) os métodos da teoria de conjuntos são uma avenida confiável para os fatos sobre conjuntos, (...) nenhuma garantia externa é necessária ou possível." [8, p. 63 - tradução nossa]. Esse tipo de consideração ontológica pode ser estendida a qualquer ramo da matemática que lida com objetos matemáticos abstratos. O realismo de Maddy assume também o terceiro excluído: sentenças são verdadeiras ou falsas. Diante disso, sentenças não decididas como a hipótese do contínuo, como qualquer sentença da teoria de conjuntos deve necessariamente possuir um valor de verdade [8, p. 63].

Isso aparece como um contraposto ao realismo robusto, pois este se baseia não somente na teoria de conjuntos, mas também na metafísica sobre conjuntos para além da matemática. Isso também pode ser dito em relação à indispensabilidade da matemática de Quine/Putnam, visto que põem outras ciências como as responsáveis por se manter uma ontologia sobre conjuntos. Ora, vimos até aqui que podemos manter uma concepção de aplicação da matemática coerente com a prática feita pelos cientistas que não afirma nem nega a existência de objetos matemáticos abstratos como consequência de uma concepção de aplicação estrutural da matemática. O mesmo vai acontecer aqui: a prática da matemática teórica pode ser interpretada de um ponto de vista realista, mas isso não confere a nenhuma ciência a capacidade de julgar sobre a existência ou não de objetos matemáticos abstratos.

O realismo fraco afirma que conjuntos existem e a teoria de conjuntos é um corpo de verdades, por exemplo. O arrealismo não afirma nada. Por outro lado, ambos possuem semelhanças metodológicas. A existência de conjuntos é sempre pressuposta durante o desenvolvimento da teoria ou posta em discussão perante a consistência da teoria. Conjuntos são uma peça importante no afazer matemático, mas não é aplicada em sua totalidade, situação que usa somente parte das estruturas.

O arrealismo e o realismo fraco estão de acordo com a prática matemática em duas frentes, pois ambos aceitam a prática matemática como está dada na aplicação nas ciências e nas questões de fundamento. A diferença é que o realista fraco acredita na existência desses conjuntos e na sua verdade "O Arrealista, assim como o Realista Fraco, formularão o axioma em forma existencial e o chamarão 'verdadeiro' (...)" [8, p. 101 - tradução nossa]. Se a matemática pura lida com objetos abstratos, deve-se aceitar esses objetos assim como qualquer outra ciência lida com objetos concretos. Essa é a posição do naturalismo pragmático: não importa ao cientista se o matemático acredita em tais objetos. A posição ontológica no naturalismo pragmático é flexível.

Para o realista fraco ou para o arrealista, não importa os aspectos científicos ou psicológicos ou religiosos para a aceitação de objetos matemáticos. O arrealista não nega a existência de tais objetos. $\mathrm{O}$ realista fraco também não. O arrealista não se importa, no caso da aplicação da matemática, com a existência de objetos matemáticos abstratos se na circunstância de aplicação isso não for algo importante. O realista pode aceitar esses objetos, mas dará uma consideração mais elaborada dessa aceitação. Ambas as considerações mostram lados diferentes da prática matemática. Um para o lado da aplicação da matemática e outro para o lado da matemática teórica. Isso mostra que durante a aplicação da matemática não são os objetos matemáticos que são importantes, portanto, o argumento de que os objetos matemáticos abstratos são indispensáveis para a aplicação da matemática, um dos componentes do holismo, perde a sua força. A matemática é realmente indispensável à ciência, mas somente as estruturas de raciocínio matemático é que são realmente importantes, o que possibilita a aplicação estrutural da matemática.

\section{Considerações Finais}

A efetividade da matemática nas ciências naturais começa a partir de uma estrutura mais geral, i.e., quando as propriedades isomórficas da estrutura matemática se encontram as regularidades selecionadas pelos físicos du- 
rante as suas investigações. As estruturas isomórficas na matemática nos mostram como é possível que os físicos lancem mão somente da sua parte estrutural.

Uma parte bem limitada dos modelos matemáticos são aplicados nas ciências naturais, sendo que a manipulação desta estrutura, feita pelos físicos, frequentemente nos fornece caricaturas da estrutura do modelo matemático original. Descrevemos os produtos linguísticos que são fruto da interação fronteiriça entre o campo disciplinar da matemática e das ciências naturais como da mesma natureza daquela estrutura linguística definida como pidgin. Assim, tomamos emprestado da linguística um termo em que o seu estudo tem lançado luz à compreensão dos estudos em outro campo, o filosófico. Isso se faz necessário porque esta linguagem hibrida comum (este pidgin) matemático-científica vai muito além de modelagem de teorias científicas de estruturas matemáticas diretamente aplicadas, de modo que podemos questionar: até que ponto poderíamos dizer que existe matemática sendo aplicada nas ciências naturais? Talvez devêssemos dizer que uma certa característica das estruturas teóricas da matemática é utilizada, em muitos casos.

A abordagem que apresentamos aqui é uma síntese a partir de vários outros argumentos citados e referenciados no corpo do texto deste artigo. Nossa contribuição foi dada através do recorte e da ênfase que demos a certos argumentos, tais como o papel das leis de invariância, regularidades e isomorfismos ao se tratar da relação entre os dois campos. O produto de nossa sistematização chamamos de abordagem pragmática estruturalista. Tal abordagem busca dar conta de explicar a efetividade do papel da matemática nas ciências naturais sem se comprometer com ontologias específicas nos fundamentos da matemática [3, p. 45]. Demonstramos, assim como já feito por Maddy [4], que nossa solução torna o holismo semântico de Quine/Putnam uma perspectiva inviável para tratar da forma como estes definem o naturalismo. Porém, dito isso, pode-se levantar o seguinte questionamento: Se as estruturas matemáticas podem funcionar como funções vazias, então qualquer objeto poderá se encaixar na estrutura? Como estabelecer o seu domínio? Aqui entra, mais uma vez, a força da argumentação pragmática. Não há método apriorístico para estabelecer os limites deste domínio. Tudo dependerá das semelhanças estruturais, ou seja, se as relações entre os objetos propostas pelo modelo matemático utilizado na física dão conta de descrever as relações observadas empiricamente, ou vice-versa. Caso as relações não se comportem exatamente como o que é exigido pelos resultados empíricos, então manipulações serão realizadas com o fim de se aumentar o grau de precisão do modelo físico em detrimento de se manter a estrutura matemática inicial. Manipulações deste tipo são feitas frequentemente na prática investigativa dos físicos e pode ser substituída por um modelo físico-matemático que nos forneça o mesmo nível de descrição ou ainda maior, sem a necessidade de manipulações arbitrárias. Esta substituição irá trazer maior confiança no poder heurístico e inferencial [5] dos desdobramentos formais do modelo físico-matemático, para prever e apontar novas estruturas na nossa descrição do mundo físico. As implicações destas afirmações foram parcialmente exploradas em uma outra publicação anterior escrita, em parceria, por um dos autores deste artigo [7].

\section{Referências}

[1] E.P. Wigner, in: Philosophical Reflections and Syntheses, editado por J. Mehra (Springer, New York, 1995).

[2] E.P. Wigner, Symmetries and reflections (Indiana University Press, Bloomington, 1967).

[3] C. Pincock, Philosophia Mathematica 12, 135 (2004).

[4] P. Maddy, Second Philosophy: A Naturalistc Method (Oxford University Press, Oxford, 2007).

[5] O. Bueno e M. Colyvan, Noûs 45, 345 (2011).

[6] D. Krause e J.R.B. Arenhart, The Logical Foundations of Scientific Theories: Languagens, Structures and Models (Routledge, New York, 2017).

[7] F. Moreira-dos-Santos e C.N. El-Hani, Filosofia e História da Biologia 8, 223 (2013).

[8] P. Maddy, Defending the Axioms: On the Philosophical Foundations of Set Theory (Oxford University Press, Oxford, 2011).

[9] W.V.O. Quine, in: Theories and Things (Harvard University Press, Cambridge, 1981), p. 67.

[10] H. Putnam, in: Realism and Reason: Philosophical Papers (Cambridge University Press, Cambridge, 1983), p. 87.

[11] P. Galison, in: Trading Zones and International Expertise: Creating New Kinds of Collaboration (The MIT Press, Cambridge, 2010), p. 25.

[12] M.A. Perini, ReVEL 8, 1 (2010).

[13] H.K. Sørensen, in: Mathematics as a Tool: Tracing New Roles of Mathematics in the Sciences (Springer, Cham, 2017), p. 69.

[14] C.S. Peirce, Popular Science Monthly 13, 203 (1878).

[15] L. Tisza, in: Experimental Metaphysics: Quantum Mechanical Studies for Abner Shimony, editado por R.S. Cohen (Kluwer Academic Publishers, Boston, 1997), v. 1, p. 213.

[16] K. Brading, E. Castellani e N. Teh, The Stanford Encyclopedia of Philosophy, disponível em https://plato.stanford.edu/archives/win2017/entries/symmetry-breaking/.

[17] M.D. Resnik, Mathematics as a Science of Patterns (Oxford University Press, Oxford, 1997).

[18] E. Nagel e J.R. Newman, A Prova de Gödel (Perspectiva, São Paulo, 2001).

[19] R.S.V. Rodrigues, ReVEL 6, 1 (2008).

[20] M. Colyvan, The Indispensability of Mathematics (Oxford University Press, Oxford, 2001).

[21] W.V.O. Quine, in: From a Logical Point of View (Harper \& Row, New York, 1961), p. 20. 